\title{
Tensile and Thermal Properties of Crosslinked Chitosan/Empty Fruit Bunch Biofilms by Phthalic Anhydride
}

\author{
Chan Ming Yeng, ${ }^{1}$ Salmah Husseinsyah ${ }^{2}$ and \\ Mohamad Arine Aizeq Ahmad Amirudin ${ }^{2}$ \\ ${ }^{1}$ Centre of Engineering Programmes, HELP College of Arts and Technology, \\ 3.01 Level 1-7, Kompleks Metro Pudu, 1 Jalan Metro Pudu 2, \\ Fraser Business Park, 55200 Kuala Lumpur, Malaysia \\ ${ }^{2}$ Division of Polymer Engineering, School of Materials Engineering, \\ Universiti Malaysia Perlis, 02600 Jejawi, Perlis, Malaysia \\ *Corresponding author: chan.ming.yeng@helpcat.edu.my
}

Published online: 25 August 2016

To cite this article: Chan, M. Y., Husseinsyah, S. \& Ahmad Amirudin, M. A. A. (2016). Tensile and thermal properties of crosslinked chitosan/empty fruit bunch biofilms by phthalic anhydride. $J$. Phys. Sci., 27(2), 67-81, DOI: 10.21315/jps2016.27.2.6

To link to this article: http://dx.doi.org/10.21315/jps2016.27.2.6

\begin{abstract}
Chitosan (CS) has high potential applications in packaging, agriculture and food. However, the cost associated with CS application is high. Therefore, the addition of agriculture waste such as empty fruit bunch (EFB) in CS has been studied in order to reduce the cost of CS. The CS/EFB biofilms are prepared through solvent casting method. This paper studies the effect of phthalic anhydride (PA) crosslinking agent on tensile, morphological and thermal properties of CS/EFB biofilms. The results indicated that the tensile strength and elongation at break of uncrosslinked CS/EFB biofilms decreases. However, the modulus of elasticity increases with the increasing EFB content. In addition, the glass transition temperature $\left(T_{g}\right)$ of CS/EFB biofilms increased with EFB content. The crosslinked CS/EFB biofilm with PA showed higher tensile properties (i.e., tensile strength, elongation at break and modulus of elasticity) in comparison with uncrosslinked biofilms. The $T_{g}$ of crosslinked CS/EFB biofilms, meanwhile, was higher than the uncrosslinked biofilms due to formation of amide linkages. The formation of amide bonds between CS and PA was analysed using the Fourier transform infrared (FTIR) spectroscopy. The better filler dispersion and filler-matrix adhesion were proven by scanning electron microscopy (SEM). It was further observed that the percentage gel fraction of both uncrosslinked and crosslinked CS/EFB biofilms increased with increasing of EFB content. On the other hand, the crosslinked CS/EFB biofilms exhibited higher gel fraction than uncrosslinked biofilms due to the formation of amide crosslinkages in crosslinked biofilms.
\end{abstract}

Keywords: Chitosan, empty fruit bunch, crosslinking, phthalic anhydride, biofilms 


\section{INTRODUCTION}

In recent years, the environmental impact caused by non-biodegradable plastic wastes has become an increasing concern globally. A lot of research has been done to develop renewable and environmental friendly bio-based polymeric materials as potential replacement for non-biodegradable plastic materials. ${ }^{1}$ Normally, these materials are made from renewable or natural resources such as wheat proteins, corn zein, gelatin, whey proteins, cellulose derivatives and chitosan (CS) are which non-toxic, biodegradable and edible. ${ }^{2}$ Moreover, these biopolymers generally exhibit high biocompatibility, biodegradability and renewability. ${ }^{3}$

CS is a natural polymer which can be obtained through deacetylation of chitin. CS is a renewable source and is abundantly available. ${ }^{4,5}$ The CS films are generally non-toxic, biocompatible and possess antimicrobial properties. ${ }^{6}$ Furthermore, CS films are tough, long lasting, flexible, and show good tear resistance. ${ }^{7}$ Because of these properties, CS is suitable material for designing packaging application. ${ }^{8,9}$

Natural fibres today are considered as a potentially genuine alternative to glass fibres as reinforcement in composite materials. Advantages of natural fibres over glass fibres include low cost, low density, resistance to breakage during processing, high strength-to-weight ratio, low energy content and recyclability. ${ }^{10,11}$ Oil palm empty fruit bunch fibres (EFBs) are available in abundance, in addition to being renewable, nontoxic, and less costly. ${ }^{12}$ In Malaysia, the palm oil industry is a major producer and exporter. ${ }^{13}$ For instance, in 2009, 85.71 million tons of fresh fruit bunches (FFBs) were produced, and an estimated amount of 6.76 million tons of dried EFBs were generated from oil palm mills. ${ }^{14}$ Therefore, the EFBs have a potential to yield up to $73 \%$ of fibres to be used as natural fillers in biocomposites. ${ }^{15,16}$

Due to poor tensile properties of uncrosslinked CS/EFB biofilms, the crosslinking agent was used in order to improve the properties of biofilms. It has been reported in our previous study that the utilisation of different crosslinking agent ${ }^{17-19}$ and addition of modifier ${ }^{4}$ in CS biocomposite films improved the tensile and thermal properties of biocomposite films.

To date, the study of EFB filled CS biofilms is not yet reported. Therefore, this paper focuses on the preparation of EFB/CS biofilms. In this study, the phthalic anhydride was used as crosslinking agent to enhance the tensile, thermal and morphological properties of EFB/CS biofilms. 


\section{EXPERIMENTAL}

\subsection{Materials}

CS was purchased from Hunza Nutriceutical Sdn. Bhd. with average particle size and degree of deacetylation of $80 \mu \mathrm{m}$ and $90 \%$, respectively. EFB was collected from Malaysia Palm Oil Board, Bangi, Selangor, Malaysia. The EFB was cleaned, crushed and ground into powder form with the particle size of $38 \mu \mathrm{m}$. Acetic acid and phthalic anhydride (PA) were supplied by Sigma-Aldrich, Penang, Malaysia.

\subsection{Preparation of Uncrosslinked and Crosslinked CS/EFB Biofilms}

First, the CS powder was dispersed into acetic acid ( $1 \mathrm{v} / \mathrm{v} \%)$ and then stirred for $30 \mathrm{~min}$. The EFB powder was then added into CS solution $(1.5 \mathrm{w} / \mathrm{v} \%)$ and stirred for $15 \mathrm{~min}$. For crosslinked CS/EFB biocomposite films with PA, the PA powder was first dissolved in ethanol to produce $1 \mathrm{w} / \mathrm{v} \%$ of PA solution. Then, $1 \%$ of PA solution was mixed with CS solution and stirred for $30 \mathrm{~min}$ and then the EFB was added. These uncrosslinked and crosslinked CS/EFB solutions were poured into plastic acrylic mold and dried in an oven at temperature $40^{\circ} \mathrm{C}$ for 24 h. Table 1 listed the formulations of uncrosslinked and crosslinked CS/EFB biofilms with PA.

Table 1: Formulations of uncrosslinked and crosslinked CS/EFB biofilms with PA.

\begin{tabular}{lll}
\hline Materials & Uncrosslinked CS/EFB biofilms & Crosslinked CS/EFB biofilms \\
\hline CS (wt\%) & $100,90,80,70,60$ & $100,90,80,70,60$ \\
EFB (wt\%) & $0,10,20,30,40$ & $10,20,30,40$ \\
PA (\%) & - & 1 \\
\hline
\end{tabular}

\subsection{Tensile Properties}

The tensile test of CS/EFB biofilms was carried out using an Instron Universal Testing machine, Model 5569, following the ASTM D 882. The specimens were cut into rectangular shape in the size of $100 \times 15 \mathrm{~mm}$. Besides, the testing was performed at $25 \pm 3^{\circ} \mathrm{C}$ with the cross-head speed of $15 \mathrm{~mm} \mathrm{~min}^{-1}$. Ten specimens were tested for each sample and the average were calculated.

\subsection{Fourier Transform Infrared (FTIR) Analysis}

The FTIR analysis was done using Perkin-Elmer, Model L1280044 instrument. The attenuated total reflectance (ATR) method was used with a spectrum 
resolution of $4 \mathrm{~cm}^{-1}$. The 16 scans in the wavelength range from 4000 to $600 \mathrm{~cm}^{-1}$ were recorded.

\subsection{Gel Fraction}

The gel fraction of each biocomposite film was determined according to the method by Ramaprasad et al. ${ }^{20}$ The specimens were swell in $1 \%$ of acetic acid for $24 \mathrm{~h}$. After that, the crosslinked portion (gel) was remains insoluble. Then, the gel was filtered and dried in oven at $50^{\circ} \mathrm{C}$ for 24 hours. The percentage of gel fraction can be calculated using equation below:

$$
\% G F=\frac{w}{w_{s}} \times 100
$$

where,

$\% G F=$ percentage of gel fraction,

$w=$ weight of gel, and

$w_{s}=$ weight of specimen before swelling

\subsection{Differential Scanning Calorimetry (DSC)}

The DSC was performed using a DSC Q 10 research instrument. The CS/EFB biofilms were cut into small pieces and weight in range of $7 \pm 2 \mathrm{mg}$. The two runs of heating and cooling scan was employed, which is first heating scanned from $30^{\circ} \mathrm{C}$ to $200^{\circ} \mathrm{C}$ and cooling scanned from $200^{\circ} \mathrm{C}$ to $30^{\circ} \mathrm{C}$; second heating from $30^{\circ} \mathrm{C}$ to $200^{\circ} \mathrm{C}$, with a heating rate of $10^{\circ} \mathrm{C} \mathrm{min}^{-1}$ in nitrogen environment. The glass transition temperature $\left(\mathrm{T}_{\mathrm{g}}\right)$ of CS/EFB biofilms were determined from DSC data.

\subsection{Scanning Electron Microscopy (SEM)}

The tensile fracture surface of CS/EFB biofilms was evaluated by using a scanning electron microscope (SEM) Model JSM-6460LA. The fracture ends of specimens were sputter coated with a thin layer of palladium to avoid electrostatic charging during examination. 


\section{RESULTS AND DISCUSSION}

\subsection{Tensile Properties}

Figure 1 exhibits the tensile strength of uncrosslinked and crosslinked CS/EFB biofilms with PA at EFB content from 10 to $40 \mathrm{wt} \%$. The tensile strength of uncrosslinked CS/EFB biofilms decreased with increasing of EFB content due to poor filler-matrix interaction and poor dispersion of EFB filler. Besides, it was found that at similar EFB content, the tensile strength of crosslinked CS/EFB biofilms with PA is higher than uncrosslinked biofilms. Moreover, at $10 \mathrm{wt} \%$ of EFB content of crosslinked CS/EFB biofilms showed higher tensile strength than neat CS film. This is due to the formation of amide linkages between PA and CS in crosslinked biofilm.

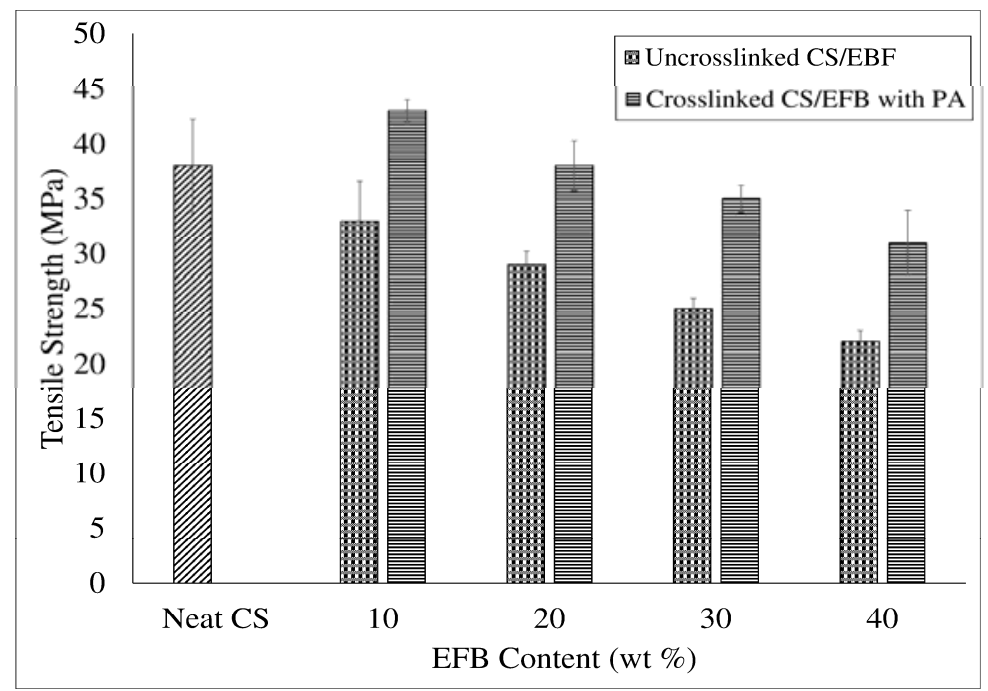

Figure 1: Tensile strength of uncrosslinked and crosslinked CS/EFB biofilms with PA.

The formation of crosslinkages in crosslinked biofilms cause the biofilms more shrinks than uncrosslinked biofilms, providing a compressive force as the CS matrix clamp down around the EFB fillers and consequently enhanced the fillermatrix interaction. These crosslinkages improved the filler-matrix interfacial interaction, and thus improved the tensile strength of CS/EFB biofilms. Besides, the chemical modification of CS/EFB biofilms with PA has also enhanced filler dispersion in CS/EFB biofilms. The average tensile strength of crosslinked CS/EFB biofilms with PA is $34.86 \%$ higher than uncrosslinked biofilms. Similar results have been reported by Yeng et al., ${ }^{17}$ who studied the effect of corn cob content and glutaraldehyde as a crosslinking agent on CS/corn cob biocomposite films. 
Figure 2 shows the influence of EFB content on the elongation at break of CS/EFB biofilms. The elongation at break of CS/EFB decreased with increasing EFB content due to the presence of natural filler, which reduced the chain mobility of CS polymer and increased the rigidity of CS/EFB biocomposite films. ${ }^{4,5,19}$ As the EFB content increased, the weak of interfacial region between filler surface and CS matrix were formed. These occurred because cracks travel more easily through the weaker interfacial region, resulting in lower elongation with the increasing EFB content. Interestingly, the elongation at break of crosslinked biofilms was higher than the uncrosslinked biofilms. This is attributed to the fact that chemical modification of biofilms with PA improved filler dispersion and thus increased the plasticisation effect of the crosslinked CS/EFB biocomposite films. Accordingly, Dearmitt ${ }^{21}$ noted that the better dispersant help to prevent agglomeration, decrease the effective particle size and thus help maintaining good elongation at break.

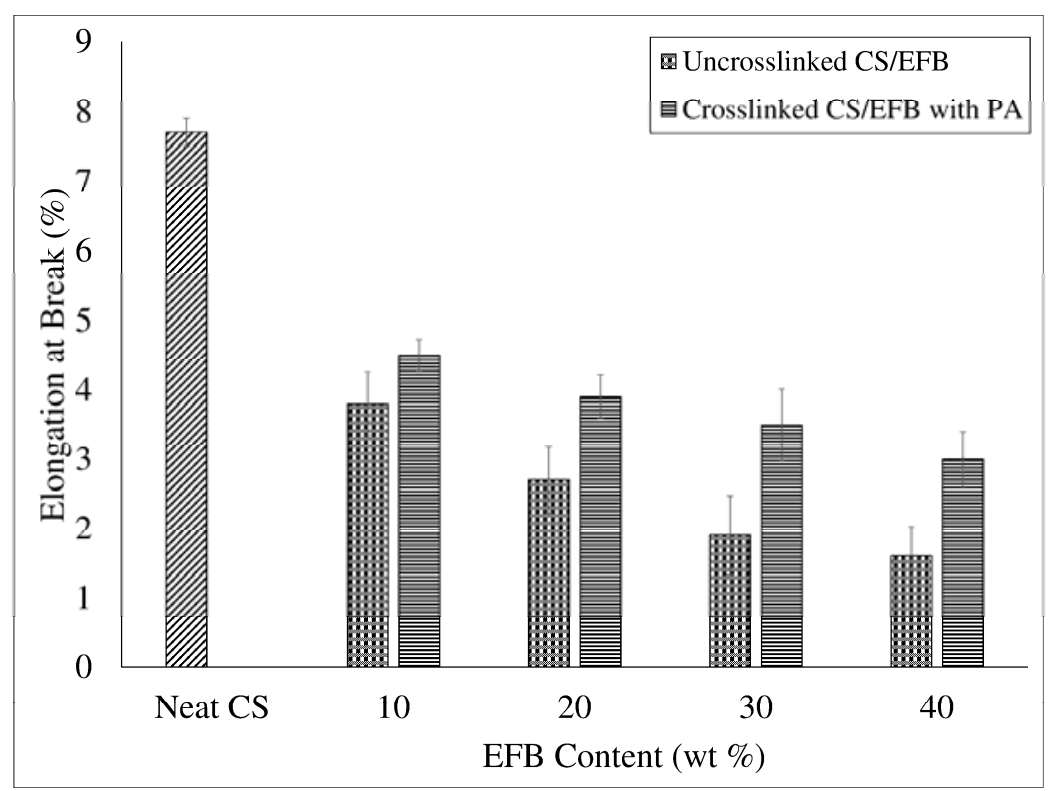

Figure 2: Elongation at break of uncrosslinked and crosslinked CS/EFB biofilms with PA.

Increase in EFB content resulted in a higher modulus of elasticity of CS/EFB biofilms, as shown in Figure 3. This result indicates that the introduction of EFB fillers decreased the flexibility of CS chain, resulting in higher stiffness of biocomposite films. Generally, the modulus of the filler is higher than the polymer matrix; thus, one of the functions of filler is to enhance the modulus of biocomposites. ${ }^{22}$ Consequently, the increment on elasticity modulus is a usually consistent behaviour in filler particle studies. As can be seen, at a similar EFB content, crosslinked CS/EFB biofilms exhibited higher modulus of elasticity than 
uncrosslinked biofilms due to formation of amide crosslinkages in biocomposite films. The crosslinked CS/EFB biofilms with PA showed around 9.92\% improvement in modulus of elasticity as compared to uncrosslinked biofilms. In short, the presence of amide crosslinkages gives a better improvement in tensile properties of CS/EFB biofilms.

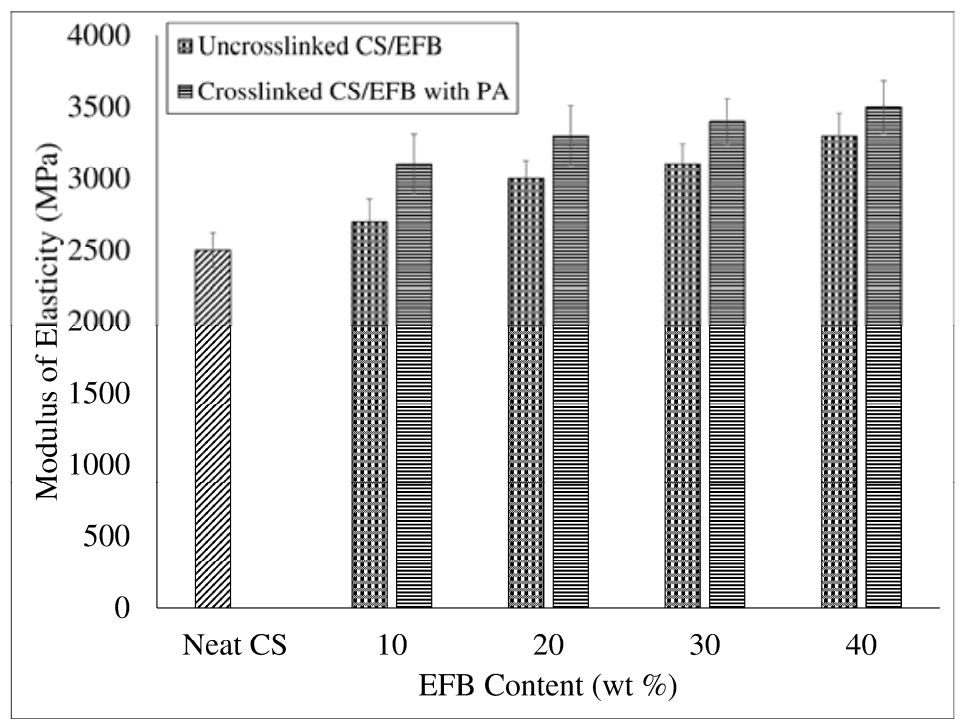

Figure 3: Modulus of elasticity of uncrosslinked and crosslinked CS/EFB biofilms with PA.

\subsection{FTIR Analysis}

Figure 4 presents the FTIR spectra of uncrosslinked and crosslinked CS/EFB biofilms with PA. Table 2 summarises the major functional groups of uncrosslinked and crosslinked CS/EFB biofilms with PA. From Figure 4, it can be observed that the band at $3323 \mathrm{~cm}^{-1}$ and $2910 \mathrm{~cm}^{-1}$ correspond to $-\mathrm{OH}$ and $-\mathrm{CH}$ groups, respectively, whereas the peaks at $1644 \mathrm{~cm}^{-1}$ and $1550 \mathrm{~cm}^{-1}$ correspond to amide I and amide II. Moreover, the peak at $1407 \mathrm{~cm}^{-1}$ is attributed to $-\mathrm{CH}_{2}$ deformation from cellulose or $-\mathrm{CH}$ group deformation from lignin. The $\mathrm{C}-\mathrm{N}$ amino and $\mathrm{C}-\mathrm{H}$ group deformations were attributed by $1327 \mathrm{~cm}^{-1}$ and $1265 \mathrm{~cm}^{-1}$. The peaks of $\mathrm{C}-\mathrm{O}-\mathrm{C}$ and $\mathrm{C}-\mathrm{O}$ groups were in the range of $1000 \mathrm{~cm}^{-1}$ to $1150 \mathrm{~cm}^{-1}$. However, the spectrum of the crosslinked CS/EFB biofilm with PA shows lower intensity peak at $3343 \mathrm{~cm}^{-1}$ compared to the uncrosslinked biofilm. This indicates that the inclusion of the PA crosslinking agent reduced the hydrophilicity of CS/EFB biofilms. 


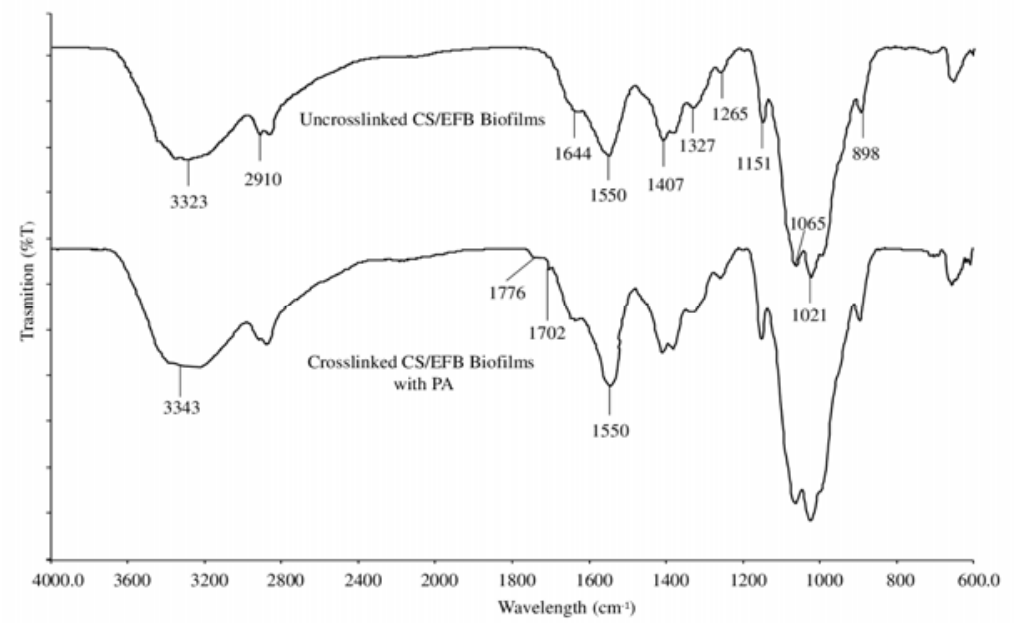

Figure 4: FTIR analysis of uncrosslinked and crosslinked CS/EFB biofilms with PA.

Table 2: The major functional groups of uncrosslinked and crosslinked CS/EFB biofilms with PA.

\begin{tabular}{|c|c|c|c|}
\hline Biofilm & Frequency $\left(\mathrm{cm}^{-1}\right)$ & Functional groups & Intensity (\%) \\
\hline \multirow{8}{*}{$\begin{array}{l}\text { Uncrosslinked } \\
\text { CS/EFB } \\
\text { biofilm }\end{array}$} & 3323 & -OH stretching & \multirow{8}{*}{-} \\
\hline & 2910 & - $\mathrm{CH}$ stretching & \\
\hline & 1644 & Amide I & \\
\hline & 1550 & Amide II & \\
\hline & 1407 & $-\mathrm{CH}_{2}$ bond & \\
\hline & 1327 & $\begin{array}{l}\mathrm{C}-\mathrm{N} \text { stretching } \\
\text { (amino group) }\end{array}$ & \\
\hline & 1265 & - $\mathrm{CH}$ stretching & \\
\hline & $1000-1150$ & $\mathrm{C}-\mathrm{O}-\mathrm{C}, \mathrm{C}-\mathrm{O}$ bonds & \\
\hline \multirow{4}{*}{$\begin{array}{l}\text { Crosslinked } \\
\text { CS/EFB } \\
\text { biofilm with PA }\end{array}$} & 3343 & $-\mathrm{OH}$ stretching & Decreased (3.2) \\
\hline & 1776 & $\begin{array}{l}\mathrm{C}=\mathrm{O} \text { stretching (from } \\
\text { anhydride) }\end{array}$ & New peak \\
\hline & 1702 & $\begin{array}{l}\mathrm{C}=\mathrm{O} \text { stretching } \\
\text { (carboxylic groups) }\end{array}$ & New peak \\
\hline & 1550 & $\mathrm{C}-\mathrm{N}$ (amide bond) & Increased (2.0) \\
\hline
\end{tabular}

Two new peaks at $1702 \mathrm{~cm}^{-1}$ and $1776 \mathrm{~cm}^{-1}$ appeared, which are ascribed to the carboxylic groups (hydrolysis products of intermediated imide) and $\mathrm{C}=\mathrm{O}$ groups from anhydride, respectively. Besides, the intensity peak at $1550 \mathrm{~cm}^{-1}$ increased due to the presence of amide crosslinkages between CS and PA overlapped with 
free primary amines. Similar finding was reported by Tangpasuthadol et al. ${ }^{23}$, who studied the surface modification of CS films by anhydride crosslinker to improve the properties of CS films. The FTIR results show a new absorption peak at $1710 \mathrm{~cm}^{-1}$ and $1770 \mathrm{~cm}^{-1}$ attributed to the $\mathrm{C}=\mathrm{O}$ stretching vibration of carboxyl groups. The proposed schematic crosslinking reaction between CS and $\mathrm{PA}$ is illustrated in Figure 5.

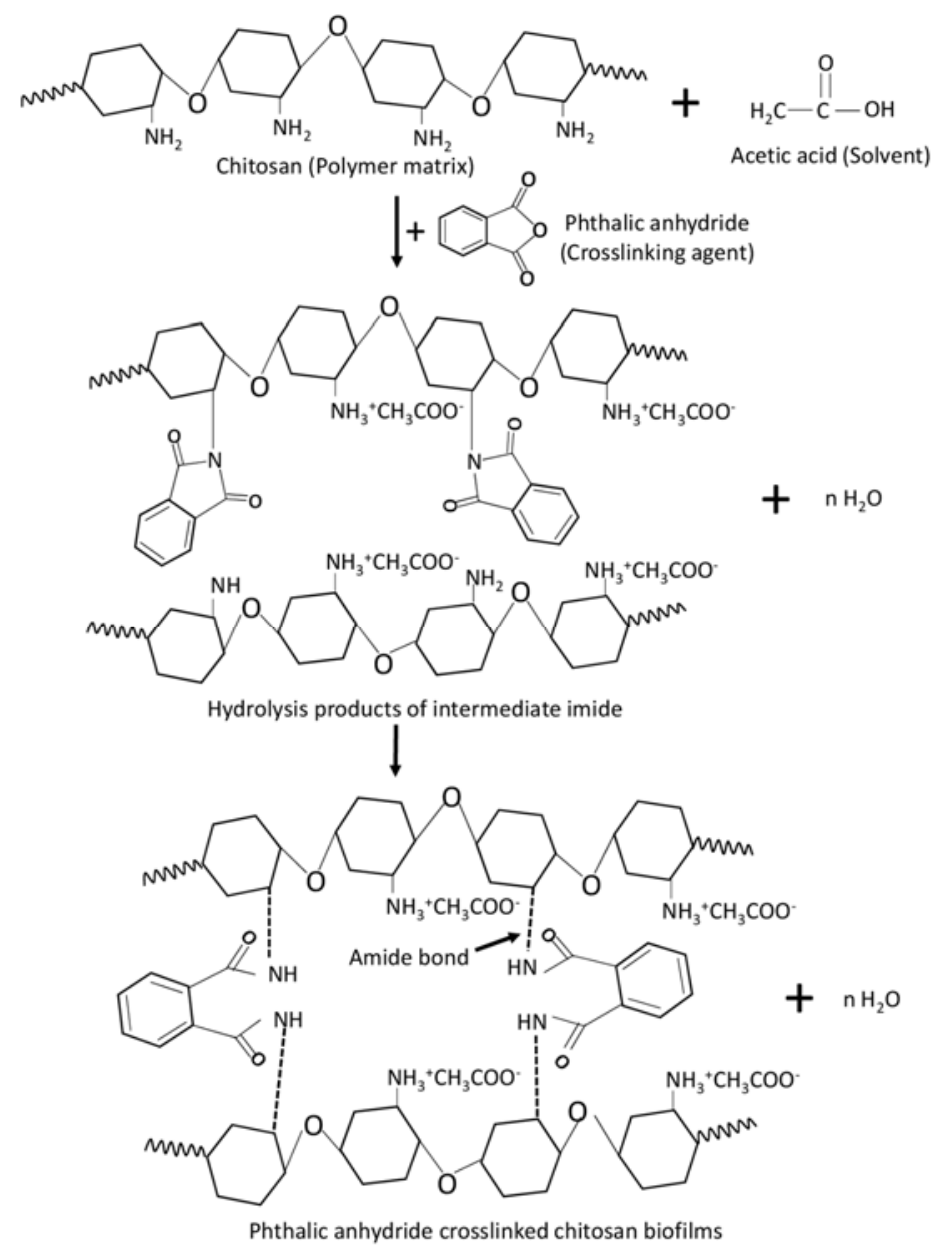

Figure 5: Proposed schematic crosslinking reaction between chitosan and phthalic anhydride.

\subsection{Gel Fraction}

In general, the gel fraction determination can be investigated the presence of crosslinkages in polymer. ${ }^{24}$ The gel fraction of uncrosslinked and crosslinked 
CS/EFB biofilms with PA is tabulated in Table 3. The gel fraction of CS/EFB biofilms increased with the increasing EFB content from $10 \mathrm{wt} \%$ to $40 \mathrm{wt} \%$ because the EFB natural filler would not dissolved in acetic acid. Nevertheless, the neat CS film was partially dissolved in acetic acid during swelling process as the CS formed a semi crystalline structure in solid state. This crystal structure hardly dissolves in acetic solution. ${ }^{25}$ On the other hand, the crosslinked CS/EFB biofilms with PA exhibited higher gel fraction in comparison with uncrosslinked biofilms. This is due to the presence of amide linkages in biofilms.

Table 3: Gel fraction of uncrosslinked and crosslinked CS/EFB biofilms.

\begin{tabular}{lc}
\hline Biofilms & Gel fraction (\%) \\
\hline Neat CS & 46.12 \\
Uncrosslinked CS/EFB (80:20) & 52.14 \\
Uncrosslinked CS/EFB (60:40) & 58.41 \\
Crosslinked CS/EFB (80:20) & 72.56 \\
Crosslinked CS/EFB (60:40) & 76.87 \\
\hline
\end{tabular}

\subsection{Differential Scanning Calorimetry (DSC)}

The DSC curve of uncrosslinked and crosslinked CS/EFB biofilms is illustrated in Figure 6. The DSC data of CS/EFB biofilms is summarised in Table 4. CS biofilms easily absorbed moisture. Thus, to eliminate the moisturising effect, two cycles of heating and cooling were introduced. Similar finding was reported by a few studies. ${ }^{26,27}$ The glass transition temperature $\left(T_{g}\right)$ of neat CS film occurred at approximately $169^{\circ} \mathrm{C}$, as shown in Table 4 . As the EFB content increased, the $\mathrm{T}_{\mathrm{g}}$ shifted to a higher temperature due to the reduction of plasticity of the CS matrix. The presence of EFB restricted the chain mobility resulting in a higher $\mathrm{T}_{\mathrm{g}}$ of CS/EFB biofilms. Nevertheless, the crosslinked CS/EFB biofilms with PA at 20 $\mathrm{wt} \%$ and $40 \mathrm{wt} \%$ of EFB content showed higher $\mathrm{T}_{\mathrm{g}}$ than uncrosslinked CS/EFB biofilms. This was due to the presence of new inters amide linkages, which become rigid and resist deforming. This observation is in line with modulus of elasticity results which was explained earlier. 


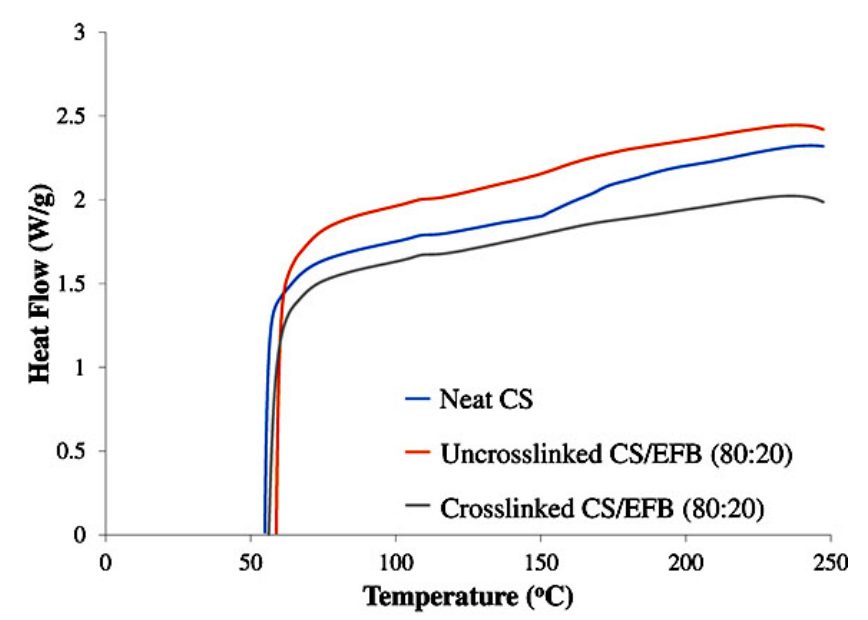

Figure 6: DSC curve of neat CS film, uncrosslinked and crosslinked CS/EFB biofilms with PA.

Table 4: DSC data of CS/EFB uncrosslinked and crosslinked biofilms.

\begin{tabular}{lc}
\hline Biofilms & $\mathrm{T}_{\mathrm{g}}\left({ }^{\circ} \mathrm{C}\right)$ \\
\hline CS & 169 \\
Uncrosslinked CS/EFB (80/20) & 156 \\
Uncrosslinked CS/EFB (60/40) & 165 \\
Crosslinked CS/EFB (80/20) & 164 \\
Crosslinked CS/EFB (60/40) & 185 \\
\hline
\end{tabular}

\subsection{Morphology Study}

Figure 7 shows the SEM micrograph of homogenous surface and matrix tearing of neat CS film. Figures 8 (a) and (b) illustrate the SEM micrograph of tensile fractured surface for uncrosslinked and crosslinked CS/EFB biofilms at $40 \mathrm{wt} \%$ EFB content, respectively. Figure 8(a) shows the rough surface with the addition high content of EFB. Additionally, the micrograph from Figure 8(a) exhibits some detachment of EFB from the CS, agglomeration and poor dispersion. This indicates poor interaction between EFB and CS matrix. This result is in line with the finding that the tensile strength of biocomposite films decreased with increasing EFB content, as discussed earlier. The SEM micrograph of crosslinked biofilm as demonstrated in Figure 8(b) shows less EFB filler detachment, less agglomeration, some embedding of EFB filler, and better dispersion in CS matrix. It can be seen that the surface is smoother as compared to without the addition of 
phthalic anhydride. This indicates that the presence of phthalic anhydride enhanced the filler-matrix interfacial adhesion and filler dispersion.

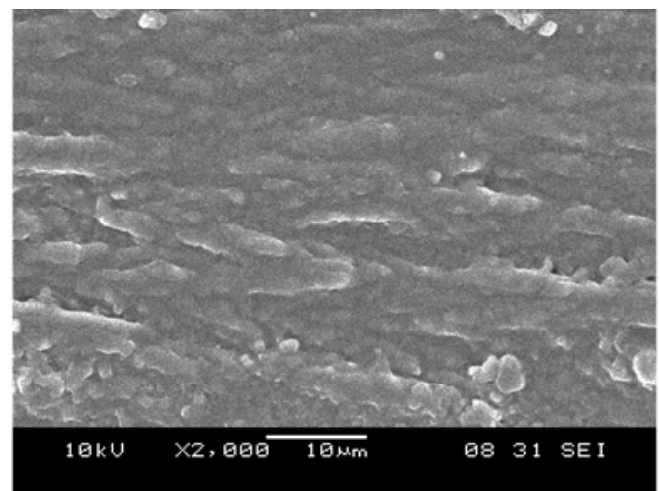

Figure 7: SEM micrograph of neat CS film.
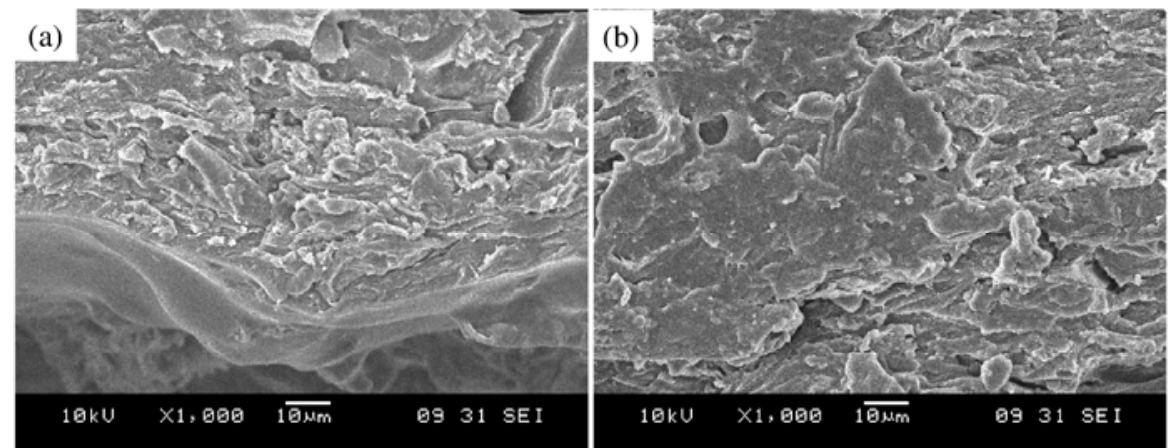

Figure 8: SEM micrograph of (a) uncrosslinked CS/EFB biofilm; and (b) crosslinked $\mathrm{CS} / \mathrm{EFB}$ biofilm at $40 \mathrm{wt} \%$ of EFB content, respectively.

\section{CONCLUSION}

In summary, changes in EFB content and chemical modification with PA had effects on tensile and thermal properties of EFB/CS biofilms. It has been found that the tensile strength and elongation at break decreased, but modulus of elasticity increased with the increasing EFB content. However, the PA improved the tensile properties of $\mathrm{EFB} / \mathrm{CS}$ biofilms due to formation of amide crosslinkages and better filler-matrix adhesion. The $T_{g}$ of biocomposite films shifted to a higher temperature with the increasing amount of EFB. After chemical modification with PA, a higher $\mathrm{T}_{\mathrm{g}}$ was observed as compared to neat $\mathrm{CS}$ film and uncrosslinked EFB/CS biofilms. The gel fraction of uncrosslinked and crosslinked CS/EFB biofilms increased with the increasing EFB content. 
Crosslinked CS/EFB biofilms exhibited higher gel fraction than uncrosslinked biofilms due to the presence of amide bonds in biofilms.

\section{REFERENCES}

1. Khwaldia, K., Arab Tehrany, E. \& Desobry, S. (2010). Biopolymer coatings on paper packaging materials. Compr. Rev. Food Sci. Food Safety, 9(1), 82-91, DOI: 10.1111/j.1541-4337.2009.00095.x.

2. Limpisophon, K. et al. (2009). Characterization of gelatin films prepared from under-utilized blue shark (Prionace glauca) skin. Food Hydro., 23(7), 1993-2000, DOI: 10.1016/j.foodhyd.2009.03.014.

3. Yu, L., Dean, K. \& Li, L. (2006). Polymer blends and composites from renewable resources. Progress Polym. Sci., 31(6), 576-602, DOI:10.1016/j.progpolymsci.2006.03.002.

4. Yeng, C. M., Salmah, H. \& Sam, S. T. (2013). Modified corn cob filled chitosan biocomposite films. Polym. Plast. Technol. Eng., 52(14), 14961502, 10.1080/03602559.2013.820752.

5. Yeng, C. M., Salmah, H. \& Sam, S. T. (2013). Corn cob filled chitosan biocomposite films. Adv. Mater. Res., 747, 649-652, DOI: 10.4028/www.scientific.net/AMR.747.649.

6. Yeng, C. M., Salmah, H. \& Sam, S. T. (2013). Effect of electron beam irradiation on the tensile properties of chitosan/corn cob biocomposite films. Adv. Environ. Biol., 8(8), 2609-2614.

7. Jeon, Y. J., Kamil, V. A. \& Shahidi, F. (2002). Chitosan as an edible invisible film for quality preservation of herring and Atlantic cod. $J$. Agric. Food Chem., 50(18), 5167-5178, DOI: 10.1021/jf0116931.

8. Aider, M. (2010). Chitosan application for active bio-based films production and potential in the food industry: Review. LWT-Food Sci. Technol., 43(6), 837-842, DOI: 10.1016/j.lwt.2010.01.021.

9. Martins, J. T., Cerqueira, M. A. \& Vicente, A. A. (2012). Influence of $\alpha$ tocopherol on physicochemical properties of chitosan-based films. Food Hydro., 27(1), 220-227.

10. Bledzki, A. V. \& Gassan, J. (1999). Composite reinforced with cellulose base fibres. Prog. Polym. Sci., 24(2), 224-274, DOI: 10.1016/S00796700(98)00018-5.

11. Ibraheem, S. A., Aidy, A. \& Khalina, A. (2011). Development of green insulation boards from kenaf fibres and polyurethane. Polym. Plast. Technol. Eng., 50(6), 613-621, DOI: 10.1080/03602559.2010.551379.

12. Rowell, R. M. et al. (1999). Properties of kenaf/polypropylene composites, kenaf properties, processing and products. Agric. Bio Eng. Chem., 32, 381-392. 
13. Bhore, S. J. (2013). Sustainable oil-palm cultivation: We need to use gene technology to boost palm-oil production. Gene Technol., 2, 1-2, DOI:10.4172/2329-6682.1000e105.

14. Kassim, M. A. et al. (2011). Bioethanol production from enzymatically saccharified empty fruit bunches hydrolysate using Saccharomyces cerevisiae. Res. J. Environ. Sci., 5, 573-586, DOI: 10.3923/rjes.2011.573.586.

15. Wirjosentono, B., Guritno, P. \& Ismail, H. (2004). Oil palm empty fruit bunch filled polypropylene composites. Int. J. Polym. Mater., 53(4), 295-306, DOI: 10.1080/00914030490429942.

16. Rozman, H. D. et al. (2001). The effect of oil extraction of the oil palm empty fruit bunch on the mechanical properties of polypropylene-oil palm empty fruit bunch-glass fibre hybrid composites. Polym-Plast. Technol. Eng., 40(2), 103-115, DOI: 10.1081/PPT-100000058.

17. Yeng, C. M., Salmah, H. \& Sam, S. T. (2013). Chitosan/corn cob biocomposite films by cross-linking with glutaraldehyde. Biores., 8(2), 2910-2923, DOI: 10.15376/biores.8.2.2910-2923.

18. Yeng, C. M., Salmah, H. \& Sam, S. T. (2015). Effect of crosslinking agent on tensile properties of chitosan/corn cob biocomposite films. Polym-Plast. Technol. Eng., 54(3), 270-275, DOI: 10.1080/03602559. 2014.977090.

19. Yeng, C. M., Salmah, H., \& Sam, S. T. (2015). A comparative study of different crosslinking agent-modified chitosan/corn cob biocomposite films. Polym. Bull., 72(4), 791-808.

20. Ramaprasad, A. T. et al. (2009). Preparation of crosslinked chitosan by electron beam irradiation in the presence of $\mathrm{CCl}_{4}$. J. Appl. Polym. Sci., 111(2), 1063-1068, DOI: 10.1002/app.29076.

21. Dearmitt, C. (2011). Applied plastics engineering handbook. New York: Elsevier.

22. Salmah, H. et al. (2014). Kapok husk-reinforced soy protein isolate biofilms: Tensile properties and enzymatic hydrolysis. Biores., 9(3), 5636-5651, DOI: 10.15376/biores.9.3.5636-5651.

23. Tangpasuthadol, V., Pongchaisirikul, N. \& Hoven, V. P. (2003). Surface modification of chitosan films: Effects of hydrophobicity on protein adsorption. Carbohydr. Res., 338(9), 937-942.

24. Ratnam, C. T. et al. (2001). Electron beam irradiation of poly(vinyl chloride)/epoxidized natural rubber blends in presence of trimethylolpropane triacrylate. J. Appl. Polym. Sci., 81(8), 1926-1935, DOI: 10.1002/app.1625.

25. Rinaudo, M. (2006). Chitin and chitosan: Properties and applications. Progr. Polym. Sci., 31(7), 603-632, DOI:10.1016/j.progpolymsci. 2006.06.001. 
26. Dong, Y. et al. (2004). Studies on glass transition temperature of chitosan with four techniques. J. Appl. Polym. Sci., 93(4), 1553-1558, DOI: 10.1002/app.20630.

27. Campos, J. B. G. et al. (2009). Dielectric relaxations of chitosan: The effect of water on the $\alpha$-relaxation and the glass transition temperature. $J$. Polym. Sci., 47(22), 2259-2271, DOI: 10.1002/polb.21823. 